\title{
ROMANTISMO COMO VISÃO FEMINISTA: A BUSCA DE CHRISTA WOLF ${ }^{1}$
}

Robert SAYRE ${ }^{2}$

Michael LÖWY3

- RESUMO: Poucos autores modernos deram tanta força de expressão à "afinidade eletiva" entre o romantismo e o feminismo quanto o fez Christa Wolf. Quando nos referimos a ela como escritora romântica, não só levamos em consideração seu interesse explícito pelas escritoras românticas do início do século XIX, como Caroline von Günderrode e Bettina von Arnim, mas também, e acima de tudo, sua própria visão de mundo romântica, e a relação desta com o marxismo e com o feminismo.

- PALAVRAS-CHAVE: Romantismo; feminismo; marxismo; República Democrática Alemã; civilização industrial.

Poucos autores modernos deram tanta força de expressão à "afinidade eletiva" 4 entre o romantismo e o feminismo quanto o fez Christa Wolf. Quando nos referimos a ela como escritora romântica, levamos em consideração tanto seu notável interesse pela tradição romântica alemã de inícios do século XIX, como também, e principalmente, sua visão de mundo romântica individual. Nossa interpretação da obra de Wolf baseia-se em uma concepção de romantismo que reconhece que ele não é apenas uma escola literária do passado, mas sim uma Weltanschauung que se espalha por todas as esferas da cultura, desde a poesia e a arte até a teologia, a filosofia e o pensamento político. Reconhecemos também que o romantismo tem sido uma importante força cultural desde a última metade do século XVIII até os dias de hoje.

Como visão de mundo, o romantismo pode ser definido como um tipo de crítica cultural da "modernidade" (isto é, a civilização capitalista/industrial/tecnológica, que teve início no século XVIII e que predomina até hoje) inspirada por valores pré-

\footnotetext{
1 Tradução de Marielza Correia da Silva (Oficina de tradução - UNESP - São José do Rio Preto; revisão da tradução por Alvaro Hattnher).

2 Professor da Universidade de Paris VI.

3 Diretor de Pesquisas no CNRS.

4 Sobre o conceito de "afinidade eletiva" em estudos culturais, ver Löwy, 1992.
} 
modernistas. O desencanto do mundo, a quantificação e reificação das relações sociais, a força destrutiva da mecanização, o reinado da racionalidade abstrata e a dissolução dos laços comunitários da civilização são alguns dos aspectos criticados ou rejeitados pelos românticos, em nome de uma infinidade de valores que incluem imaginação, experiência subjetiva, fantasia, comunidade e reintegração com a natureza. Esse protesto impetuoso contra certas características fundamentais da modernidade faz alusão a valores sociais ou culturais atribuídos ao passado, mas não é, necessariamente, regressivo; o romantismo pode assumir formas revolucionárias ou conservadoras, utópicas ou restauradoras. ${ }^{5} \mathrm{O}$ romantismo de Christa Wolf pertence à corrente utópico-revolucionária, mas reinterpretado sob formas feministas.

Nem sempre o romantismo e o feminismo foram relacionados na mesma configuração intelectual. Muitos autores românticos, voltando a um passado patriarcal, celebraram os papéis femininos tradicionais, colocando em oposição o feminismo e a emancipação feminina (Proudhon, Ruskin e muitos outros). Por outro lado, as feministas sempre foram atraídas pela interpretação igualitária e modernista do liberalismo e até mesmo do utilitarismo, principalmente graças ao fato de alguns de seus expoentes apoiarem abertamente a luta pelos direitos das mulheres (John Stuart Mill). Entretanto, desde o início existia um romantismo "filogínico" (Charles Fourier), assim como determinadas escritoras que estavam ao mesmo tempo preocupadas com a emancipação das mulheres e atraídas pelo romantismo (Elizabeth Barrett Browning, Georges Sand, as irmãs Brontë). Christa Wolf pertence a esta última tradição, embora seu estilo de pensamento e escrita tenha muito pouco em comum com as grandes romancistas do século XIX.

Apesar de sua diversidade e inegável evolução, a obra de Wolf como um todo é, na verdade, caracterizada de diversas maneiras e em diferentes medidas por essa dupla perspectiva: o feminismo e o romantismo na dimensão utópico-revolucionária (no caso de Wolf, ele toma a forma de um humanismo marxista, mais especificamente). Sua carreira literária, até o presente, se estende por mais de três décadas (tendo início em 1960), e inclui muitas formas distintas de expressão: romances, contos, esboços autobiográficos, ensaios, entrevistas e ainda obras que extrapolam esses gêneros e que não se encaixam perfeitamente em nenhuma categoria preestabelecida. Se olharmos para essas obras em seqüência cronológica, imediatamente perceberemos determinados avanços que levaram os críticos a falar, por exemplo, de uma passagem do realismo para o modernismo em estilo literário, e de uma posição relativamente não crítica quanto à RDA para uma atitude intensamente crítica, entre outras coisas. Da mesma maneira, no que diz respeito à visão e ao quadro de referências de Wolf, Anna Kuhn (autora do primeiro estudo integral da obra de Wolf a aparecer em inglês) indicou uma evolução tanto "do marxismo para o feminismo" quanto do "iluminismo para o romantismo". 6

5 Apresentamos, inicialmente, nossa interpretação do romantismo em Sayre \& Löwy, 1984. Esse artigo gerou um debate que pode ser encontrado na coleção de ensaios publicada por Rosso \& Watkins, 1990. Mais recentemente, desenvolvemos nossa tese em um livro publicado na França, Sayre \& Löwy, 1992.

6 Kuhn, 1988. A primeira sentença é o subtítulo de sua obra, e a segunda aparece na p.26. 
Seria absurdo dizer que as obras de Wolf não mudaram com o tempo, e sobre isso, o estudo de Kuhn sobre o desenvolvimento da carreira de Wolf, incluindo análises detalhadas de suas obras, é muito esclarecedor. Mas as afirmações de Kuhn parecem sugerir uma dicotomia alternativa, com o feminismo e o romantismo substituindo o marxismo e o iluminismo, ao passo que afirmaríamos que existe uma continuidade subjacente à obra de Wolf (com a qual Kuhn está em freqüente sintonia). Afirmariamos ainda que, a esse respeito, podemos encontrar, cada vez mais desenvolvidas, a consciência e a elaboração de uma problemática romântica e feminista, as quais estavam presentes desde o início, em forma de sementes. Por outro lado, o amadurecimento da percepção feminista e romântica não anulou as perspectivas marxistas/iluministas, mas sim as reinterpretou e as integrou em um contexto no qual foi alterada a ênfase ou o centro de gravidade.

Em uma das palestras sobre seu romance Kassandra (em 1983), Wolf compara sua recente abertura à consciência feminista com sua iniciação no marxismo:

Com a ampliação de meu ângulo visual e o reajuste de minha profundidade de foco, minhas lentes ... passaram por uma mudança decisiva, que é comparável àquela que aconteceu há mais de 30 anos, quando tive meu primeiro contato com as posturas e a teoria marxistas, uma experiência esclarecedora e libertadora que mudou meu modo de pensar, de ver, e também meus sentimentos e exigências para comigo mesma. (1984, p.278) ${ }^{7}$

O mais importante aqui é que Wolf fala, por meio da metáfora de uma câmera, sobre a segunda percepção, a feminista, como uma ampliação e um aprofundamento de foco, em vez de ser a substituição de uma lente por outra totalmente diferente. Em outras palavras, ela não diz, de maneira alguma, que o feminismo toma o lugar do marxismo em seu universo mental. Da mesma forma, quando a questionaram, durante um debate nessa mesma época (1983), sobre a crítica de alguns segmentos que diziam que ela estaria fazendo um "retorno" antiiluminista ao romantismo, ela respondeu que essa era uma "visão pouco dialética", e negou que ela, naquele momento, e até mesmo o movimento histórico dos românticos anteriores (e o Sturm und Drang) fossem basicamente antiiluministas (1988b, p.111).

Seu contato com tendências românticas históricas - pelo menos na forma do Sturm und Drang - data de sua época de estudante (fim da década de 1940 e início da de 1950); segundo Wolf, foi o último movimento (e especialmente o jovem Goethe) considerado politicamente progressista que pôde ler na época e que se tornou um "modelo". Foi somente bem mais tarde que conheceu os românticos alemães do início do século XIX (p.112).

Ainda como estudante, na Universidade de Leipzig, sofreu a influência de dois professores marxistas heterodoxos, Hans Mayer e Ernst Bloch, que também podiam ser caracterizados como românticos utópico-revolucionários. Em 1987, referindo-se a Hans Mayer, Wolf delineou seu relacionamento com ele iniciado por estudos sob

7 Para uma descrição de sua descoberta do marxismo, ver Wolf, 1972, p.47-53. 
sua orientação e seguindo com a publicação de Aussenseiter (1975), de Mayer, muito admirado por ela. Ainda nessa fala, afirma que, assim como Mayer, foi puxada para o movimento comunista pelo "desejo" (Sehnsucht) de pertencer a uma "comunidade" (Gemeinschaft) (1988a, p.42). Quanto a Ernst Bloch, a incidência crucial de sua filosofia sobre as obras de Wolf tem sido muito ressaltada, principalmente por Jack Zipes e Andreas Huyssens. Em particular, os conceitos interligados de Bloch sobre Heimat (terra natal) e a não ainda alcançada aufrechter Gang (postura ereta) da humanidade, que juntas formam uma configuração utópico-romântica quintessencial, são também parte integrante da visão de mundo de Christa Wolf. ${ }^{8}$

Apoiando-se na tradição romântica em seus estágios inicial e final, Wolf desenvolve sua própria visão por meio de um processo de reapropriação e reinterpretação feminista. A seguir, tentaremos explorar melhor o processo contínuo (cronologicamente partindo de seus trabalhos iniciais até os mais recentes) dessa dupla elaboração entrelaçada de feminismo e romantismo utópico-revolucionário.

No primeiro texto criativo publicado por Wolf, "Terça-feira, 27 de setembro", é espantoso que já se encontrem indicações de sensibilidade romântica e também feminista. Nessa obra, que fez parte de um concurso literário promovido pelo jornal soviético Izvestia sobre o tema "Sua rotina no dia 27 de setembro de 1960", a narradora comenta que, em uma reunião da direção do Partido Comunista na fábrica onde trabalha, alguém levanta a hipótese de convidar mulheres para uma importante reunião da brigada, mas apenas porque "está na moda". Publicamente ninguém poderia contestar isso; contudo, fica claro que a sugestão não encontra nenhum defensor fervoroso. "As mulheres já não têm bastante trabalho com as crianças?" diz um deles (Wolf, 1993, p.35). No final do texto, a narradora fala da dificuldade em escrever um texto muito longo (o que mais tarde virá a ser Der geteilte Himmel), pois é incapaz de dar vida à banalidade da rotina da fábrica, que é seu assunto. Essa banalidade opressiva de sua realidade diária é contrastada, no último parágrafo, com aquilo que ela fica a imaginar pouco antes de adormecer:

aparece uma rua que leva àquela paisagem que conheço tão bem sem nunca ter estado lá: a colina com a velha árvore, o declive que se inclina levemente para o riacho, o prado e a floresta no horizonte... Sempre vou achar triste não podermos vivenciar de verdade esses momentos antes de adormecer - se isso acontecesse, não adormeceríamos. (p.39)

Essa busca de comunhão com a natureza, visão utópica de integração com o mundo natural, estará presente em toda a obra posterior de Wolf.

O primeiro romance, Moskauer Novelle (1961), celebra, na verdade, a feliz união de sua heroína com aquele mundo e com uma comunidade humana solidária. Vera, uma pediatra da Alemanha Ocidental que visita a Rússia soviética com um grupo de compatriotas, se envolve nessa ocasião com Pawel, um russo que conhecera ainda

8 Ver J. Zipes, 1976, e o ensaio "Auf den Spuren Ernest Bloch. Nachdenken über Christa Wolf", de Huyssen, 1979, p.81-7. Para um estudo da visão romântica de mundo de Bloch, ver Sayre \& Löwy, 1992, cap.6. 
menina, e se apaixona pela zona rural russa e também por Pawel. A natureza ao redor se identifica com as pessoas, vistas como um todo lírico: "Isto aqui é a vida, pensou Vera nostalgicamente (sehnsüchtig). Este sol, esta terra e estas pessoas" (p.21). Quando o grupo visita um colcós é muito bem recebido e festejado, e Vera sente ser parte daquilo que parece ser uma comunidade alegre, e une-se mais intensamente aos outros membros do grupo por fortes laços de amizade. Diferente de "Terça-feira, 27 de setembro", Moskauer Novelle não problematiza a realidade do "socialismo real", e é, em muitos pontos, uma glorificação deste como um campo para a realização da aspiração romântica.

Ainda assim, o quadro que nos é mostrado no romance não é entretanto tão simples. Em uma passagem central, os personagens discutem as qualidades que imaginam que os seres humanos socialistas futuros apresentarão. Pawel afirma, usando o jargão de Bloch, que o Homem finalmente "andará ereto (aufrecht) sobre a terra" (p.54); e acrescenta que a característica mais importante do novo ser humano será a "irmandade" (Brüderlichkeit). As relações humanas não serão competitivas e duvidosas. A idéia de um futuro de comunicação aberta e afetiva sugere implicitamente um contraste com o presente; em Moskauer Novelle a liberdade permanece utópica, isto é, o ainda-não-alcançado segundo Bloch. ${ }^{9} \mathrm{O}$ caso de amor entre Vera e Pawel mostra os principais traços dessa utopia, mas apenas como uma premonição fugitiva, ou Vorschein. Marca uma interrupção em suas vidas normais, sobre as quais pouco sabemos, e para as quais retornam voluntariamente no final.

Com Der geteilte Himmel (1963), separado de Moskauer Novelle pela construção do Muro de Berlim, o tom se torna mais abertamente crítico; agora, o centro das atenções começa a ser a vida "comum" no "socialismo real". A apreciação da vida próxima à natureza do romance anterior torna-se, aqui, uma consciência infeliz das alienações da vida na cidade e das incursões da indústria poluente até mesmo no campo. A heroína Rita, vinda de uma cidadezinha que ama, com "a quantidade exata de florestas, campos, prados e céu límpido" (Wolf, 1976, p.11), é confrontada com a solidão ao mudar-se para a cidade, e também com a feiúra das visões e odores industriais, tanto dentro como fora da cidade.

Divided Heaven é bastante ambíguo em sua percepção da sociedade da Alemanha Ocidental em relação ao desejo romântico e também ao impulso feminista. Por um lado, coloca-se uma oposição entre os trabalhadores e o ambiente profissional burguês. Os trabalhadores mostram devoção e desprendimento idealista num esforço hercúleo para construir uma nova sociedade (Meternagel é comparado a um "herói de uma lenda antiga, designado para uma tarefa aparentemente impossivel") (p.75), enquanto os professores são fúteis, egotistas e oportunistas. Os trabalhadores são, em princípio, igualitários no que diz respeito aos gêneros - Rita se impressiona com

9 Anna Kuhn (1988, p.26) afirma algo parecido com isso. Jack Zipes (1976) bem nota nessa passagem uma chave para o entendimento de Moskauer Novelle, e também para todos as obras posteriores de Wolf. 
a divisão paritária das tarefas domésticas pelo casal Schwarzenbach - enquanto as esposas dos professores são objetos de dominação. Os professores são identificados com o Ocidente capitalista, para o qual Rita se recusa emigrar em virtude de este representar a ganância e a total falta de comunidade, ideal e esperança (assim como a alienação da natureza: significativamente, ela tem o triste e acabado jardim na Alemanha Ocidental, no qual diz adeus a Manfred, como símbolo do Ocidente).

Por outro lado, há uma inegável tendência oculta em se questionar o fato de a Alemanha Oriental poder ou não poder ser realmente uma alternativa viável para sua contraparte ocidental. Além da poluição que maltrata o meio ambiente, predomina a mentalidade produtivista, tecnocrática, proveniente do Ocidente (afinal, é apenas para aumentar a produção industrial que os trabalhadores se sacrificam). O ponto de vista de Manfred (o que as pessoas realmente desejam é "uma casa que funcione tão bem quanto uma máquina lubrificada") é hegemônico; ele emigra para o Ocidente apenas porque lá eles fazem a mesma coisa, mas melhor. Até mesmo Schwarzenbach admite, no fim do romance, que "às vezes pensamos que estamos mudando algo, quando o que estamos fazendo é, na verdade, trocando os nomes" (p.106, 203). A conclusão põe em questão também as relações homem-mulher entre os trabalhadores, quando Rita visita a esposa de Meternagel e descobre o quanto custa para ela essa devoção monomaníaca ao aumento de produtividade (p.216-7). ${ }^{10}$

Embora com isso Divided Heaven realmente dê um passo à frente de seu predecessor, quanto a analisar criticamente "o socialismo real", continua, pelo menos em parte, dentro do quadro do Bildungsroman social-realista, com uma Rita amadurecida voltando a executar sua função socialista no final da obra. A crítica romântica e feminista dá um outro salto crucial no romance seguinte de Wolf, Nachdenken über Christa T. (1968), no qual, pela primeira vez, a heroína é uma "marginal" (como será nos próximos romances), uma "deslocada" que é incapaz de se integrar na sociedade, mas que é mostrada como a encarnação de valores que poderiam ajudar aquela sociedade a se tornar aquilo que realmente deveria ser.

Christa T. mostra muitos traços românticos característicos, alguns dos quais já haviam aparecido em heroínas anteriores (amor pela natureza, atração por simples camponeses, empatia com crianças proveniente do contato com a criança presente nela mesma etc.). Algumas características, principalmente a busca de expressão própria e autoconhecimento, uma abertura do eu para a experiência, estão muito mais marcadas em Christa T. do que nas heroínas anteriores. Mas, com ela, também vem à tona uma área quase que completamente nova: a fantasia, a arte, o poder transformador da imaginação. O novo interesse no jogo livre da imaginação, na verdade, já havia sido mostrado de forma marcante em "Juninachmittag" (1965), quando a família do narrador participa de um jogo de palavras (semelhante àqueles feitos pelos surrealistas), no qual recombinam os elementos de expressões fixas, estereotipadas, de

10 Ver, também, Kuhn, 1988, p.46. 
forma a produzir absurdos sugestivos e admiráveis; quando o jogo se volta para os clichês e para a terminologia política, logo se transforma em sátira. ${ }^{11}$

Em Christa T. a imaginação envolve um movimento duplo: de um lado, saudade nostálgica (escolhe estudar Theodor Storm, pois sua obra é uma "paisagem de desejo [Sehnsucht]" lírica, e perto do fim de sua vida ela mesma escreve histórias sobre comunidades tradicionais de camponeses próximas de seu novo lar) (Wolf, 1988c, p.97171), e, de outro, a abertura de possibilidades. Ela se recusa a aceitar limites e se entrega a sonhos infinitos sobre coisas que poderiam e deveriam acontecer (para ela a imaginação também apresenta uma dimensão moral) (p.114), uma atividade que Bloch denomina "orientada para o futuro": sonhar "para a frente" (nach Vorwärts). É nesse sentido que sua vida e sensibilidade romântica (claramente não políticas, embora seja adepta do socialismo e fuja do Ocidente capitalista) apresentam influência política. Ela é uma reprovação viva à sociedade alemã-oriental por encarnar a luta pela liberação humana que essa sociedade afirma estar construindo, e ser, ao mesmo tempo, incapaz de viver nessa sociedade como realmente é.

Muitas críticas feministas têm sugerido que sua consciência também apresenta conteúdo feminista. Myra Love, particularmente, demonstrou de maneira marcante que, embora Wolf não use o termo "patriarcal" até dez anos após a publicação de The Quest for Christa T., tanto a personagem Christa T. como a narradora (por meio do processo no qual ela recria Christa T., e ao fazer isso muda a si mesma) derrubam todo um conjunto de oposições alternativas, mutuamente exclusivas, que marcaram as culturas patriarcais. O amor também indica o potencial utópico da consciência feminina de Christa T.: "Ao determinar o tipo de subjetividade incorporado por Christa T., a narradora também determina, por meio de um processo de solidariedade, o potencial utópico de uma subjetividade feminina histórica" (Love, 1979). O tema do amor levanta semelhanças palpáveis entre o romance de Christa Wolf e a obra de muitas feministas do Ocidente (Adrienne Rich e Mary Daly). I. Ezergailis (1982) faz o mesmo em um livro que estuda Ingeborg Bachmann, Doris Lessing e outras, e seu livro explica, mais detalhadamente, a "afinidade eletiva" entre o feminismo e o romantismo, pois embora não use o termo, revela, nas autoras estudadas, a configuração arquetípica romântica: sentimento de perda e o desejo de recriar um paraíso perdido de plenitude.

Não é fácil saber a extensão da reação de Christa Wolf para com a dimensão romântica dos eventos europeus de 1968; de qualquer forma, nesse ano ela escreveu seu ensaio "The Reader and the Writer", que traz uma das mais belas exposições sobre o ethos romântico-utópico: "Guardamos para nós mesmos uma lembrança de tempos passados (Vor-Zeiten), que trazia um modo de vida mais simples e sereno, essa memória forma nossa imagem nostálgica do futuro..." (1980, p.45-6). Sehnsuchtbild von der Zukunft: não se pode imaginar um resumo mais chocante da ligação dialética romântica entre passado e futuro, nostalgia e utopia.

11 Ver "June afternoon", em Wolf, 1993, p.53-4. 
A invasão soviética na Tchecoslováquia e o clima interno quase insuportável na Alemanha Oriental - The Quest for Christa T. de Wolf havia sido condenado pela liderança do Partido Comunista na Sexta Conferência de Escritores na Alemanha Oriental em maio de 1969 - criaram o contexto histórico para uma nova etapa de sua evolução intelectual e literária, caracterizada por um posicionamento crítico aguçado e um crescente interesse pela tradição romântica alemã. Outros escritores da RDA também partilhavam de preocupações semelhantes a essas. Na verdade, as idéias de Wolf faziam parte de um modelo mais amplo, que inclui outros escritores de renome da RDA, como Heiner Müller, Volker Braun e Cristoph Hein; durante os anos 70 e 80, cada um deles desenvolveu, à sua maneira, uma crítica de reificação e alienação que foi inspirada pelo protesto romântico contra a zivilisation moderna (e, até certo ponto, inspirada pela crítica da Escola de Frankfurt da razão instrumental). Todos pareciam acreditar que as limitações ou falhas do socialismo da Alemanha Oriental eram resultado de um rompimento incompleto com a civilização ocidental. E essa visão apocalíptica da história direcionou toda sua força para a utopia. Confrontada por uma civilização ocidental condenada pela maldição de sua destruição utilitária, o salto para o "diferente" tornou-se uma questão de sobrevivência para a espécie humana. ${ }^{12}$

A própria versão de Christa Wolf sobre esse modelo é sutilmente colorida pela ironia romântica e subversão feminista. Um das primeiras obras dessa nova etapa é o conto "Neue Lebensansichten eines katers" (1981b), escrito em 1970. Inspirado pela obra-prima irônica de E. T. A. Hoffmann, Lebensansichten des katers Murr (citada na epígrafe), o conto é uma sátira mordaz da ideologia tecnoburocrática e "científica".

Max, o gato que conta a história, partilha com entusiasmo das visões de seu dono, Prof. R. W. Barzel e seus sócios, Dr. Lutz Fettback (uma visível referência ao termo feedback usado em cibernética), dietista e fisioterapeuta, e Dr. Guido Hinz, sociólogo cibernético. Seu objetivo é grandioso: nada mais, nada menos que TOFEHUM (Total Felicidade Humana)! Infelizmente, a espécie humana atual não alcançou maturidade suficiente para compreender suas necessidades e precisa ser forçada a ser feliz. Isso acontecerá graças à introdução (obrigatória para todos) de um sistema exclusivamente científico e à prova de erros, chamado SISACEM (Sistema de Saúde Corpórea e Espiritual Máximas).

Como deve ser implantado o SISACEM? Segundo os três ilustres estudiosos, é preciso apenas eliminar alguns aspectos inúteis e supérfluos da vida humana. Por exemplo, a alma (Seele), uma ilusão reacionária, que serve apenas para certificar uma existência útil para campos econômicos improdutivos - como a literatura (Belletristik). O mesmo se aplica a outras idéias ou valores anacrônicos e pré-científicos como "pensamento criativo", "audácia", "altruísmo", "compaixão", "orgulho". O resultado desse processo de purificação será o "ser humano normalizado" (Normalmensch), um ser puramente reflexivo que responde a estímulos de maneira totalmente previsível.

12 Sobre esse tópico, ver o ensaio interessante (mas antipático) de Herziger \& Preusser (1991), sobre "A literatura da RDA na tradição da crítica alemã da civilização". 
Em outras palavras: o objetivo é uma programação completa do espaço de tempo que as pessoas designam pela palavra arcaica VIDA. A té agora a humanidade tem tido uma atitude mística e irracional para com esse espaço de tempo; essa atitude leva à desordem, à perda de tempo e a um gasto desnecessário de força. Agora, graças ao SISACEM, temos um sistema logicamente inevitável de conduta de vida racional, aplicando a técnica mais recente de cálculo (1981b, p.97-123).

As mulheres não parecem compartilhar da crença dos três cientistas, e de seu discípulo felino, o gato Max, sobre as qualidades do SISACEM. Em geral, como reconhece com tristeza o Prof. Barzel, elas parecem resistir com teimosia aos métodos experimentais mais avançados da ciência. Isa, a filha mais nova do professor, formula, com precisão, sentimentos femininos sagazes, ao chamar o pai de Fortschrittsspiesser (filisteu em evolução) (p.98, 115).

Ao ridicularizar esse tipo de projeto "científico", Christa Wolf não somente satiriza a ideologia positivista das elites dominantes do Oriente e do Ocidente, como também chama a atenção para os perigos da desumanidade tecnológica e da padronização autoritária que resultam de um certo tipo de racionalidade instrumental. Assim como o Murr de E. T. A. Hoffmann, o gato Max de Wolf é um instrumento irônico para desmascarar a tentativa filistina de eliminar a imaginação e os sentimentos humanos em nome da "razão".

"Neue Lebensansichten eines Katers" é uma das três histórias publicadas com o subtítulo de "Drei unwahrscheinlichen Geschichten" ["Três histórias improváveis"]. Em uma conversa com Hans Kaufmann, Christa Wolf nos fornece algumas pistas importantes sobre sua intenção:

Escrevi as três histórias entre 1969 e 1972, e elas representam aquela fase de meu trabalho ... Espero que sua "improbabilidade", seu caráter sonhador, utópico e grotesco produzam um efeito alienador para com determinados processos, circunstâncias e idéias que, por terem se tornado tão familiares, não notamos e nem nos incomodamos mais com eles. E, na verdade, eles deveriam nos incomodar - e digo isso com a firme convicção de que podemos mudar aquilo que nos incomoda. (1988b, p.36)

O terceiro conto "improvável", "Self-Experiment" (1978), também é uma crítica ao "cientificismo", mas dessa vez tendo como assunto principal a questão dos gêneros. É a primeira de suas obras que apresenta um ethos abertamente feminista e antipatriarcal. A história deve acontecer em um futuro próximo (o ano é 1992!), quando o progresso científico permitirá, graças a uma nova droga ("Peterine Masculinum 199"), a transformação de mulheres em homens. O texto é uma carta escrita ao professor que coordena o projeto por uma das cientistas que participam do grupo de pesquisa, que aceitou servir como cobaia. A carta é uma descrição de seus sentimentos e reações durante o experimento e também uma reflexão mais geral sobre as relações entre os gêneros. Como um homem, ela (ou melhor, ele) tem um caso com a filha do professor, mas após algumas semanas, um sentimento da "absurda falta de lógica" da experiência leva-o/a a interromper o estudo e voltar à condição feminina. 
Ela então passa a entender bem mais que o professor, e seus assistentes do sexo masculino compartilham uma "adoração supersticiosa a resultados previsíveis"; estão aprisionados em sua "rede de números, diagramas e cálculos". Acreditando na neutralidade científica, tentam permanecer frios, distantes e impessoais; segundo a narradora, o segredo de sua invulnerabilidade é a indiferença. Para eles, mulheres problemáticas, que hesitam entre a felicidade no amor e a necessidade de trabalho, são como um "mouse de computador que foi mal programado", ziguezagueando de um lado para outro. Eles não entendem "o espírito demoníaco que se apossou de mim e fez que eu deixasse prematuramente o experimento de sucesso".

De volta à sua natureza feminina, a narradora opõe "as palavras de minha linguagem interna" à neutralidade irreal do discurso "científico". Repudia a atitude de impassividade e não-envolvimento dos cientistas e critica seu modo de vida:

Sem saber e sem querer, trabalhei como um espião em território inimigo e, com isso, descobri aquilo que deve continuar sendo seu segredo para que seus convenientes privilégios continuem inviolados: que a atividade na qual vocês se envolvem não pode trazer felicidade, e que temos o direito de resistir quando vocês tentam nos induzir a ela.

Ao mesmo tempo, ela rejeita a perigosa divisão do trabalho que "dá às mulheres os direitos da dor, histeria e da grande maioria das neuroses, ao conceder-lhes o prazer de lidar com os desdobramentos da alma (que ainda não foram vistos em microscópio)" e com as belas artes - enquanto, por outro lado, os homens se voltam para as realidades: negócios, ciências e política mundial (p.113, 120-2, 127-8).

Essa "história improvável" tem alguns elementos fundamentais em comum com "Neue Lebensansichten eines Katers": o protesto romântico contra o domínio tirânico da forma quantificadora e calculista, fria e impessoal da moderna racionalidade técnica e científica. Como salientou Christa Wølf, em um comentário sobre Selbstversuch, o que está sendo questionado na história são "certos tipos de pensamento positivista que se escondem por trás do chamado método natural científico e ignoram os aspectos humanos" (1988b, p.35). Entretanto, seu tom é radicalmente diferente do conto anterior. Não é irônico ou satírico, mas revela desconforto e até mesmo amargura. E o ponto essencial não é o absurdo dos planos para o direcionamento científico da alma, e sim a ligação íntima entre essa ideologia positivista e a hierarquia patriarcal.

O conto "Self-Experiment" também é uma contribuição para o contínuo debate entre feministas quanto à escolha entre igualdade ou diferença como vetor principal da liberação da mulher. A heroína do experimento não nega a necessidade de igualdade, mas critica a tendência "assimilacionista" das mulheres emancipadas, sua imitação dos padrões de comportamento masculinos. Nas conversas com Hans Kaufmann, acima mencionadas, Christa Wolf faz alguns comentários bastante pessoais sobre esse tópico: 
As questões que tentei levantar c'om minha história buscam saber se o objetivo da emancipação feminina para as mulheres deveria ser "tornarem-se semelhantes aos homens"... Com a melhora das condições materiais que permitem um início igual para ambos os sexos, e esse deve ser o primeiro passo para a emancipação, encaramos com mais precisão o problema de se dar a todos a oportunidade de serem diferentes, de reconhecer que possuem necessidades diferentes, e que homens e mulheres, e não somente os homens, são modelos de seres humanos. Isso não acontece nem mesmo com a maioria dos homens, e na verdade muito poucas mulheres questionam e chegam ao porquê de suas consciências estarem sempre perturbadas (pois não podem fazer o que se espera que façam). Se chegassem ao âmago da questão, descobririam que é sua própria identificação com uma masculinidade idealizada que está, na verdade, obsoleta. (p.34-5)

Em sua introdução à primeira tradução inglesa de Selbstversuch (em New German Critique, inverno de 1978), Helen Fehervary e Sara Lennox sublinham a dimensão feminista da história, e também a reinterpretação do marxismo, feita por Wolf, por meio da experiência feminina. ${ }^{13}$ Entretanto, deve-se acrescentar que os valores inspiradores de sua utopia marxista/feminista e sua rejeição dos modos de vida positivista/patriarcal estão profundamente enraizados na tradição romântica de Zivilisationskritik. Essa ligação, já sugerida em suas primeiras obras, irá se tornar central nos próximos trabalhos: No Place on Earth e os ensaios sobre as correspondências de Karoline von Günderrode e Bettina von Arnim.

Kein Ort. Nirgends (escrito em 1977) é uma das expressões mais interessantes, dentro da literatura da segunda metade do século XX, da continuidade subterrânea entre o Frühromantik próximo ao início do século XIX e o romantismo de nossos tempos, o que, é claro, não quer dizer que não haja diferenças significativas. Apesar das inúmeras citações de Kleist e seus amigos que aparecem nos diálogos, o romance é totalmente "moderno", quanto ao estilo, conteúdo e significado.

Por que uma escritora alemã-oriental dos anos 70 sentiu a necessidade de escrever um romance sobre um encontro imaginário entre Kleist e Karoline von Günderrode? A escolha de Christa Wolf deve ser localizada no contexto político e cultural específico da RDA daquela época. Por muitos anos, a entrada do romantismo na RDA foi dominada pela estética do realismo de Lukács, que rejeitava a tradição romântica no geral e, principalmente, as obras de Kleist, taxando-as de subjetivistas, irracionalistas e reacionárias. Já em 1937, Anna Seghers havia contestado essa visão, em sua correspondência (publicada) com Lukács, mas sua afirmativa era marginalizada pela doutrina vigente. Foi apenas nos anos 70 que começou a existir uma nova aproximação com o romantismo por escritores alemães-orientais e historiadores lite-

13 "Wolf extrai da vida das mulheres um potencial de experiência e conhecimento totalmente novo .... O que se chamou de marxismo 'crítico', 'humano' ou 'utópico' em sua obra representa sua percepção feminina da história, e os 'traços' e 'esperanças' utópicas comentados por Bloch em suas obras teóricas revestem-se de um caráter material indestrutível na realidade de mulheres intermediadas por Wolf. E isso, na verdade, é o próprio radicalismo das obras de Wolf, não como uma alternativa ao marxismo, mas, sim, como uma dimensão autônoma e qualitativamente nova, que é pré-requisito para sua renovação" (Fechervary \& Lennox, 1978, p. 111-2). Sobre Ernst Bloc e Christa Wolf, ver o ensaio "Auf den Spuren Ernst Blochs. Nachdenken über Christa Wolf", de Huyssen, 1979, p.81-7. 
rários, o que pode ser visto como parte de uma tendência geral à crítica cultural da ideologia oficial. ${ }^{14} \mathrm{O}$ romance e os ensaios de Christa Wolf são relacionados a esse movimento, mas ao enfocar escritoras românticas virtualmente ignoradas pelo cânon literário alemão (como Karoline von Günderrode ou Bettina von Arnim) e seu conflito com as normas patriarcais, Wolf bate em uma nova tecla e cria seu próprio, único e singular universo literário.

Entretanto, também há um fundo político em seu interesse pessoal nos românticos: a situação criada pela expulsão do poeta e cantor dissidente Wolf Biermann da RDA. Em novembro de 1976, em resposta a essa medida arbitrária, um grupo de escritores e intelectuais, entre eles Stephan Hermlin, Christa Wolf, Gerhard Wolf (marido de Christa) e Sara Kirsch, enviou uma carta aberta de protesto para o jornal oficial do Partido Comunista e para a agência de notícias francesa, intimando as autoridades a reconsiderar sua ação. Em represália a esse primeiro protesto público coletivo, Christa Wolf e outros escritores de renome foram expulsos da diretoria da agência da União dos Escritores em Berlim. O vice-ministro da Cultura, Klaus Höpcke, chamou os assinantes da petição de "inimigos do socialismo". E, após alguns meses, Gerhard Wolf foi excluído do Partido Comunista.

Para Christa Wolf, esses eventos magoaram-na intensamente (logo em seguida, ela veio a sofrer um ataque cardíaco) e foram um ponto crucial para a alteração de suas relações com a estrutura de poder da RDA. A partir daquele momento, ela passou a sentir-se marginalizada, como os escritores românticos em relação a suas sociedades. Como disse a Frauke Meyer-Gosau em uma conversa alguns anos mais tarde, ela tentou ligar essa experiência pessoal a alguns padrões gerais de civilização moderna:

O que mais me interessava era investigar quando teve início essa terrível separação entre indivíduos e sociedade ... Na sociedade industrial ... nem as mulheres nem os intelectuais possuem qualquer influência sobre os processos básicos que determinam nossas vidas. Foi a severidade dessa transformação em marginal que senti em minha própria vida, é isso que gostaria de estudar ... Onde e quando começou? Nas obras e na vida dos românticos encontramos muita documentação sobre isso, eles sentiam que eram marginalizados, que não eram necessários em uma sociedade que passava por um processo de transformação para se tornar uma sociedade industrial, para intensificar a divisão de trabalho, para transformar pessoas em acessórios de máquinas ... O fato de que realmente podemos notar semelhanças com nossas próprias reações ... impeliu-me a dar esse tão falado salto no passado. (1988b)

Em outras palavras, os primeiros românticos, e principalmente as mulheres entre eles, por meio de sua notável sensibilidade humana, já haviam descoberto alguns dos aspectos negativos da sociedade industrial moderna que começava a se cristalizar no século XIX. Voltando às suas obras, podemos encontrar as raízes dos problemas atuais, tanto no Oriente como no Ocidente. Segundo Christa Wolf (ainda nessa

14 Ver Kuhn, 1988, p.142: "Dessa forma, NoPlace on Earth podeser visto como parte de uma tentativa de reabilitação dos românticos por parte da vanguarda literária socialista". Ver, também, Trotten, 1982. 
entrevista), existem algumas necessidades humanas básicas que não são satisfeitas pelos sistemas econômico e social dos dois estados alemães:

Por exemplo, a necessidade de ... poesia na vida das pessoas. De tudo aquilo que não pode ser simplesmente contado, medido ou colocado em termos estatísticos. A literatura tem aqui sua função como meio de auto-afirmação ... E voltamos novamente ao caminho que nos leva ao romantismo. (p.91-2, 100)

Os romances e ensaios de Christa Wolf do fim dos anos 70 são considerados românticos não apenas por tematizarem a vida de poetas e escritoras de 1804, mas também por darem expressão literária à profunda afinidade eletiva com os dilemas, valores e aspirações desesperadas dos Primeiros Românticos. Ao mesmo tempo, seu interesse específico pelas escritoras e poetas reflete o amadurecimento da consciência feminista, a crescente preocupação com assuntos relacionados aos gêneros e às estruturas patriarcais (Kuhn, 1988, p.143, 174).

Faremos, agora, um exame mais direto de No Place on Earth. A estrutura do romance é, de certa forma, estática: descreve um encontro imaginário entre Heinrich von Kleist e Karoline von Günderrode (que em breve cometeria suicídio), em 1804, na casa de um mercador, Merten, em Winkel no Reno. Entre os convidados, estão o poeta Clemens Brentano, Savigny, o filósofo do Direito (casado com Gunda, irmã de Clemens), o médico Wedekind e o cientista Nees von Esenbeck. Günderrode tivera um envolvimento emocional com Savigny, mas tenta soltar-se dessa ligação. No decorrer da tarde, ela e Kleist aproximam-se movidos por um sentimento comum de insatisfação com a conversa banal no salão-de-chá. Saem juntos para uma caminhada, quando revelam um ao outro seus sentimentos, idéias e dúvidas mais íntimas. Logo se separam, e Kleist volta para Mainz. A primeira parte do romance é composta principalmente por monólogos interiores de Kleist e Günderrode, e apenas na última parte acontece um tipo de diálogo real entre eles.

As duas figuras poéticas e trágicas são colocadas em forte contraste com as outras, e principalmente com o que chamaríamos os "filisteus" da festa do chá. Faz-se um contraste humano e também filosófico correspondente ao choque entre valores românticos e o estilo de vida dominante. Joseph Merten, "comerciante atacadista de temperos e perfumes", patrono das artes e ciências, é o tipo ideal de burguês filisteu: em sua inocência, não consegue entender por que a poesia não pode ser escrita com a mesma ordem e transparência de seus livros de contabilidade, "por que as regras que já foram testadas e experimentadas em uma área não seriam válidas em outra área?". Nees von Esenbeck é o típico "filisteu científico", que rejeita, em nome da "tendência dos tempos" e do "progresso das ciências", as "lamentações hipocondríacas dos cavalheiros literários"; seu único desejo é viver duzentos anos mais tarde, na condição paradisíaca que a humanidade irá desfrutar, graças ao desenvolvimento da ciência. E, por fim, Savigny (o fundador da arquiconservadora Escola de Direito Histórica) parece representar o intelectual filisteu que insiste na idéia de que deveríamos manter bem diferenciados o campo do pensamento do campo da 
ação, e que se recusa categoricamente a medir a vida por meio de um ideal (Wolf, 1981a, p.43, 50-1, 78-80).

Contra esse fundo cinza e conformista, a figura de Kleist aparece como a encarnação de uma ordem espiritual superior. Apesar de suas hesitações e ambigüidades políticas (entre Napoleão e Prússia), ele acredita em determinados valores com os quais não consegue se comprometer. Quando Merten sugere que viva com o lucro de sua produção literária, responde com "veemência inesperada" que se recusa a "escrever livros por dinheiro". Explica a Savigny que não pode aceitar as idéias em vigor sobre o que é nobre e o que é vil: "Trago em meu peito uma lei, contra a qual todas as externas, ainda que feitas por um rei, não possuem valor algum". E, em um debate com Esenbeck, Savigny critica com ferocidade a "unilateralidade ciclópica" das disciplinas científicas, elogiando a sede humana da sabedoria e iluminação: "sem o Aufklärung, o ser humano é pouco mais que um animal". Entretanto, como a maior parte dos românticos, ele acredita que a ciência foi pervertida pela sociedade moderna: "assim que entramos na esfera do conhecimento, parece que um feitiço maligno vira contra nós o uso que fazemos de nosso aprendizado" (ibidem).

O estado mental de Kleist é de desespero. Profundamente desapontado por suas experiências na França e na Prússia, não acredita que possa encontrar um lugar na Terra onde possa se encaixar: "Vida impossível. Kein Ort. Nirgends". Na verdade, a questão não é tanto de lugar e sim de tempo: é o Zeitgeist que torna a vida tão deprimente. E é este o ponto em que ele, intuitivamente, sente que Karoline von Günderrode partilha de seus sentimentos. Enquanto pessoas como Merten "louvam as vantagens dos novos tempos em relação ao tempos passados ... acredito que eu, Günderrode, eu e você sofremos com os males dos novos tempos" (p.65, 80-1, 86, 108).

A Günderrode de Christa Wolf é um espírito rebelde. Quando quer soltar as amarras de dependência de Savigny, ele reclama dos "sentimentos republicanos" dela (os quais define como "um resquício da Revolução Francesa") e de sua "independência extravagante" (outrierte Selbständigkeit). Mas ela se agarra com todas as forças a essa autonomia orgulhosa, que tem como terrivel limite o punhal que sempre traz consigo, para poder acabar com sua vida a qualquer momento. Em um de seus poemas (publicado com o pseudônimo masculino de "Tian"), classifica como desleais as pessoas (como Savigny) que, com "consciência fria" (Kalt Bewusstsein), "julgam, calculam e medem" coisas do amor. Diferente dos artistas que buscam apenas glória e sucesso, a poesia é, para ela, produto de uma necessidade íntima, de um desejo intenso e nostálgico (Sehnsucht) de expressar sua vida de um modo eterno (p.50, 59, 75).

Enquanto os outros homens na festa do chá (Clemens Brentano, Savigny) a tratam como objeto, um tipo de "propriedade particular", ela encontra na conversa com Kleist a possibilidade de uma comunhão humana significativa (não necessariamente erótica). "O diálogo entre Kleist e Günderrode, o clímax de No Place on Earth, se distingue das conversas na casa de Merten (que, para os dois, são fúteis), por se tratar de uma troca entre intelectuais iguais que conseguem ver um ao outro como indivíduos 
autônomos" (Kuhn, 1988, p.164-5). Além das barreiras de identidade e hierarquia sexual, dois seres humanos se encontram e mostram um ao outro seus sentimentos e idéias mais profundos. O diálogo a seguir faz parte da luta romântica e utópica em comum:

[Kleist]: Sempre penso: e se, devido à nossa organização, a primeira condição ideal (Idealzustand), produzida pela Natureza e que tivemos que destruir, nunca nos levar até a segunda condição ideal?

[Günderrode]: Se deixarmos de ter esperança, então acontecerá aquilo que mais tememos. (Wolf, 1981a, p.117) $)^{15}$

É difícil não ouvir nessa última sentença um eco da filosofia de esperança de Bloch. Embora muitos dos diálogos de No Place on Earth sejam mais ou menos citações literais das obras e correspondência das figuras históricas, Christa Wolf certamente selecionou e reinterpretou este material sob a influência de sua própria sensibilidade crítica e feminista.

Ao mesmo tempo que escrevia seu romance, Christa Wolf preparava uma coleção das obras de Karoline von Günderrode (poemas, prosa, cartas), que publicou no mesmo ano, 1979, com o título (extraído de uma das cartas) Der Schatten eines Traumes [O espectro de um sonho]. Esse também é o título do ensaio que introduz o livro, um dos textos mais brilhantes de Wolf. Não basta dizer que ele ilumina o romance e também traz à tona seu contexto histórico. É uma jóia rara da crítica e da literatura e uma contribuição decisiva para a redescoberta da vida e obra da jovem poeta romântica que se suicidou em 1806, aos 26 anos. Além disso, revela as razões do grande interesse de Christa Wolf pelo romantismo alemão inicial, e mostra ainda a atualidade desse universo cultural em relação aos problemas do mundo contemporâneo.

Em primeiro lugar, ela enfatiza o forte caráter antiburguês do movimento. Os românticos de 1800 formavam um pequeno grupo de intelectuais, "uma vanguarda sem apoio como só houvera, na história alemã, durante as Guerras dos Camponeses", que travou uma guerra perdida contra a posição tacanha da burguesia alemã (uma classe subdesenvolvida que, do catecismo burguês, só aprendera um mandamento: fiquem ricos!), que tinha como único interesse moral "sintonizar a desvairada busca de lucros com as virtudes luterano-calvinistas da diligência, frugalidade e disciplina". Essa geração se rebelara contra o racionalismo árido da época (parecido com nosso materialismo vulgar), um pacato "estado mental superficial" (Plattheit) que fingia explicar tudo, mas não compreendia nada, contra a abstração congelada e a irresistível consolidação de estruturas destrutivas, contra o "insensível pensamento utilitário" (erbarmungslose Zweckmässigkeitsdenken). Ou seja, contra todos os aspectos da modernidade que levam ao medo, depressão e autodestruição (Wolf, 1981c, p.7-10).

Wolf cita um poema filosófico de Karoline von Günderrode como testemunho da reação dessa geração romântica contra o "rebaixamento do grande clímax inte-

15 O diálogo é construído de tal forma que fica difícil saber sempre quem está falando, e este procedimento enfatiza a comunhão espiritual dos dois escritores românticos. 
lectual do Aufklärung alemão a um raciocínio pragmático inferior (pragmatischer Vernünftelei)", na visão de mundo pálida e monótona de agora: "Der Himmel ist gestürzt, der Abgrund ausgefüllt, Und mit Vernunft bedeckt, und sehr bequem zum gehen" (p.10). ${ }^{16}$

Também em oposição ao feudalismo de mente fechada e ao espírito tristemente ganancioso (tristen Erwerbsgeist) dos novos tempos, Günderrode sonha com um paraíso perdido: "Para mim, nossa época é chata e vazia; uma dor nostálgica (sehnsuchtsvoller Schmerz) me puxa com força para o passado". Como poeta romântica, ela é destinada a tornar-se marginal e, de suas relações emocionais complexas com três homens (Clemens Brentano, Karl von Savigny, Friedrich Creuzer) não abstrai nada além de (em suas próprias palavras) "o espectro de um sonho". Segundo Wolf, podemos sentir em suas cartas e poemas o desejo desesperado de que "entre homens e mulheres possam existir outras relações além da dominação, subordinação, ciúme, propriedade; relações igualitárias, amigáveis, solidárias". Luta, por meio de suas obras, para ser um ser autônomo, mas "o processo para se tornar um indivíduo vai contra a natureza do Zeitgeist, que busca utilidade, valorização (Verwertbarkeit), a transformação de todas as relações em valores de câmbio. Como se houvessem lançado um feitiço sobre pessoas e coisas" (p.13-22).

Ao ler a correspondência entre Günderrode e suas amigas (Lisette Nees, Bettina von Arnim), Wolf chega à conclusão que essas jovens mulheres, as primeiras intelectuais, "sentem o começo da era industrial, a divisão do trabalho e a divinização da Razão como uma violação de sua natureza". E só agora as marcas que deixaram podem ser percebidas, aceitas e compreendidas. Não é por acaso que foi justamente sobre as mulheres que caíram os males dos tempos. Sua marginalidade econômica, a impossibilidade de lutar por uma posição, um cargo público libertava-as da necessidade de legalizar o espírito de subordinação (Untertanen-Ungeist). Por meio de uma estranha mudança, nasceu, de uma situação de total dependência, "um pensamento totalmente livre, e utópico", transportado poeticamente para o sonho de Karoline von Günderrode: "Sim, deverá haver uma época na qual cada ser estará em harmonia consigo mesmo e com os outros". A poesia, diz Wolf, possui afinidade com a essência da utopia, pois apresenta "uma inclinação ao mesmo tempo dolorosa e prazerosa para o perfeito" (p,28-9, 51).

Günderrode foi tirada do esquecimento por sua amiga Bettina von Arnim, que publicou uma versão revisada de sua correspondência em 1840. Em um posfácio à reedição desse livro (Die Günderrode), em 1980, Christa Wolf escreveu um ensaio sobre essa outra notável escritora, muitas vezes citada apenas por seu relacionamento com algumas figuras masculinas (irmã de Clemens Brentano, amiga de Goethe, esposa de Achim von Arnim), cujas obras estão entre as poucas que mantêm vivo, durante a primeira metade do século XIX, o radicalismo do início do romantismo. Pela

16 "Os céus desmoronaram; o abismo está cheio e coberto pela razão, bom lugar para se andar." 
sua atenção para com os pobres e proletários, Bettina foi acusada de "comunismo", e seus livros foram proibidos pelas autoridades prussianas; "A insensível mecanização que foi transportada do crescente sistema maquinário para as relações sociais e para os seres humanos era, para ela, uma abominação". ${ }^{17}$

Ao falar sobre essa correspondência, Wolf se mostra fascinada pelo modo com o qual as duas mulheres românticas "co-filosofaram" sobre uma "religião baseada na humanidade e no prazer de viver", radicalmente oposta ao culto masculino da agressão. A amizade entre elas era uma experiência utópica, uma tentativa de dar vida a um tipo diferente de razão e progresso, um tipo de aufklärerischen Denkens em oposição à "unilateralidade do pensamento instrumental e reificado" e aos "insensíveis mecanismos de uma filosofia que mata todos os tipos de sentimento (geisttötenden)"; ambas sonhavam com uma alteração para a exploração da natureza, a inversão dos fins e dos meios e a repressão de todos os elementos "femininos" da nova civilização. A melancolia das obras de Bettina e o suicídio de Günderrode são testemunhos dessa batalha perdida (1980, p.312-4).

Esses dois ensaios constituem uma das mais brilhantes e bem articuladas tentativas de Christa Wolf de descobrir as raízes comuns, a secreta solidariedade, a íntima relação entre o protesto romântico e a utopia feminista.

Com a publicação de Kassandra, em 1983, pode-se dizer que todo o processo de maturidade da integração do ponto de vista romântico utópico e feminista chega a seu ápice. Nessa obra, as duas tendências, que haviam se tornado cada vez mais perceptíveis nas últimas obras de Wolf (mas que estavam presentes desde o início), atingem sua forma mais consciente, explícita e elaborada, e apresentam-se, também, muito mais interligadas e entrelaçadas, tornando-se, assim, aspectos igualmente importantes de uma única e mesma visão. Enquanto em No Place on Earth Wolf havia se ligado a uma primeira tradição romântica, em Kassandra expressa o foco principal do impulso romântico-utópico: busca inspiração no passado para imaginar um futuro que pode transcender o presente degradado. É neste ponto que aparece com mais clareza a estrutura geral da visão romântica. Também agora o feminismo de Wolf, que até certo ponto permanecera latente nas produções anteriores, vem a ser expresso de maneira aberta e vigorosa, como um dos enfoques centrais da obra.

Kassandra é uma seqüência de cinco conferências apresentadas por Wolf na Universidade de Frankfurt em 1982: as quatro primeiras feitas a partir de narrações e reflexões sobre suas recentes viagens à Grécia e leituras sobre a cultura da antiga Grécia, e a última delas é um pequeno romance que reinterpreta a lenda de Cassandra. Os quatro primeiros textos foram inicialmente publicados à parte, com o título de Voraussetzungen einer Erzählung, mas Wolf (1988b, p.118) deixara claro que esses textos e o romance "formam juntos um todo estético". A edição inglesa, da qual faremos as citações, publica os cinco textos em um mesmo volume, mas coloca o romance na frente, apesar de o termo que designa os outros textos (Voraussetzungen) implicar precedência. Ao discutir a obra, iremos, portanto, retomar a ordem original.

17 Ver: "Nun Ja! Das nächste Leben geth aber heute an. Ein Brief über die Bettine", em Wolf, 1980, p.287, 311. 
No prefácio de Voraussetzungen, Wolf (1984, p.142) afirma que em Kassandra "minha primeira preocupação são os sinistros efeitos da alienação...", e as leituras preliminares são, na verdade, antes e depois, um quadro da alienação, um retrato vago do "barbarismo da era moderna" (p.159). Começando por sua inquietação com a atmosfera anti-séptica do aeroporto e do avião, um microcosmo de sociedade no qual ninguém se preocupa com ninguém, a narrativa da viagem marca sua descoberta da Grécia moderna, desfigurada pela poluição (que rapidamente destrói as lembranças do passado, inclusive os locais mais sagrados, como a Eleusis) e feiúra arquitetônica ("cubos de concreto", indicando que o sentido grego de beleza cedeu lugar ao "domínio da eficiência sobre todos os valores") (p.203). Encontra em Atenas uma "cidade superpopulosa, apressada, homicida e ávida por dinheiro, que vomita fumaça e gás carbônico, tentando estar em dia... [com países mais 'avançados']"; nessa cidade, o que une as "mônadas da cidade" é "a caça das dracmas" (p.159-60). Em reflexões posteriores, Wolf desenvolve suas idéias sobre a civilização moderna de forma mais geral, e enfoca claramente a mecanização e a alienação do trabalho, a ideologia da "cientificidade" e a burocracia. Dentro dessa civilização, ela evoca particularmente a "súplica desesperada" das mulheres, que se encontram em pior situação que a de Kassandra, vítima de um estágio inicial do desenvolvimento moderno (p.151, 195).

Wolf nota a presença de alguns aspectos da antiga vida: várias ciganas que levam "um círculo de parentesco onde quer que estejam" (p.163), ou ainda a cidadezinha tradicional que visitou na Grécia. Mas isso, a seu ver, não representa uma solução; nesses lugares, a comunidade e os valores significativos também implicam total submissão das mulheres. Para ela, a crença religiosa é impossível, os paraísos modernos são "mudos e sem sentido" (p.158), assim como é impossivel a "aventura", e também como todas as outras coisas, com exceção de "uma aventura no pensamento" (p.199); Wolf toma parte de uma aventura como essa ao tentar a viagem imaginária, da Grécia moderna aos tempo antigos.

Essa jornada ao passado mostra que o período homérico, da Guerra de Tróia e da lenda de Cassandra (que virá a ser seu tema), já está "atrasado": isto é, nesse tempo, as primeiras mutações históricas determinantes já haviam acontecido no caminho que leva à modernidade. A civilização clássica grega adora "falsos deuses", semelhantes aos nossos (p.237). Em determinada passagem, Wolf questiona quando foram os "pontos de mutação" (e também se eles eram inevitáveis); embora não tente precisar historicamente o momento, ou os momentos, de transição, nessa e em muitas outras passagens ela procura definir a natureza desse fato. Torna-se clara, aqui, a ligação integral entre o feminismo e o romantismo no pensamento de Wolf, pois ela vê esse processo como se envolvesse simultaneamente o advento do patriarcalismo e de uma série de características que mais tarde irão se transformar na civilização moderna e capitalista: a propriedade particular, a hierarquia de classes, a busca inicial de eficiência econômica e de "mais produtos a cada dia" (p.251, 282, 296). Em termos psicológicos e ideológicos, essa mudança foi acompanhada pela divisão do corpo, alma e espírito. 
Antes que essas mudanças desastrosas acontecessem, existiam matriarcados agrícolas que cultuavam a fertilidade e deusas da terra, nas quais a magia era praticada por senhoras idosas ou por sacerdotisas, e nas quais prevalecia uma correlação holística de todos os aspectos da vida. Esse período, que Wolf sugere ser o início da humanidade (pois foi então que o gênero humano desenvolveu sua especificidade em relação a seus ancestrais animais), exerce uma visivel fascinação sobre ela (assim como o matriarcado minóico, também por ela comentado). E, ao mesmo tempo, ela sente dificuldade em distinguir sua posição daquela de algumas feministas radicais (no texto, representadas pelas americanas Sue e Helen), que fazem dessas culturas de Ur terras prometidas idealizadas. Ela sabe que a sociedade minóica incluía hierarquia feudal e escravidão, e os matriarcados agrícolas primitivos eram pré-racionais e ainda não conheciam o egoísmo individual. O fato de Wolf não aceitar tais sociedades como modelo, e ainda prevenir contra os perigos do puro "irracionalismo", mostra bem como sua perspectiva romântica integra por completo a Aufklarüng em si mesma.

Sua visão é, assim, essencialmente voltada para o futuro, para a criação de um futuro que, mesmo trazendo consigo o passado, seria basicamente novo, uma $\mathrm{Au}$ fhebung do passado. Nas conferências contidas em Kassandra, Wolf suscita a questão desse futuro, e pergunta se existe alguma alternativa para o "barbarismo" da modernidade. Ela é tomada por dúvidas e acredita que uma futura mudança na vida, uma nova renascença, é uma mera possibilidade, difícil de se crer na atual situação. Sua única certeza é de que esse novo futuro, se vier a acontecer, será um fenômeno humano generalizado (ela rejeita terminantemente o sectarismo feminista e o particularismo) e também um futuro no qual as mulheres terão um papel central, pela contribuição de aspectos positivos da consciência feminina historicamente formada. a última das conferências preliminares termina avisando que "palavras" de mulheres que "poderiam ter o poder de lançar feitiços" (p.305) são ameaçadas pelo risco de as mulheres virem a pensar como homens, fazendo que, em vez de igualdade formal, os homens continuassem a reinar por meio da perpetuação de sua mentalidade de modernidade destruidora. Wolf afirma que essa é "a mensagem de Cassandra para hoje".

Essa estrutura de sentimento utópico-romântica é articulada, em termos ficcionais, na novela Kassandra - a dinâmica de um presente que está decaído em relação ao passado, e após o qual se abre a possibilidade (mas apenas uma possibilidade) de um futuro diferente. A principal diferença entre as conferências e o romance nesse aspecto é que, enquanto aquelas não mostram nenhum encrave político na realidade atual, Wolf consegue projetar na ficção tais encraves dentro de sua Tróia imaginária. Essa Tróia, descrita na Ilíada, já foi corrompida pelos vícios da modernidade, e na verdade pode ser lida como uma alegoria de nosso próprio mundo.

Certa vez esse passado é chamado de uma "Época Dourada" da "antigüidade longínqua", antes de acontecer uma "sucessão de eventos que arrasaram nossa cidade ... sob a soberania de uma sucessão contínua de reis..." (p.37). Dessa forma, o patriarcado já está bem estabelecido em Tróia na época da guerra, assim como no campo dos inimigos gregos. Uma das funções de Wolf ao recontar a Guerra de Tróia 
é, na verdade, desmitificar o "herói" patriarcal, revelando sua hipocrisia, covardia e brutalidade. Também já se encontra bem firmada em Tróia (assim como na Grécia) a mentalidade mercantil: Cassandra associa lembranças de sua infância, o "cheiro limpo e ascético de meu pai" com "as mercadorias que vendíamos ou transportávamos ... os resultados de nossa renda e as discussões sobre como iríamos gastá-la" (p.13-4). Ao mesmo tempo, Tróia, durante a guerra (e até mesmo antes da guerra propriamente dita), mostra as marcas do estado autoritário; Eumelos lidera esse aparato ao engajar-se na quase-orwelliana manipulação da linguagem e reescrita da história, e também ao ordenar a perseguição e posterior prisão de Cassandra.

Existe nessa sociedade completamente alienada (ou quase completamente, visto que há alguns sinais de que os troianos não se tornaram tão corruptos quanto os gregos) uma contracultura utópica: as mulheres que secretamente cultuam Cibele, uma antiga deusa da fertilidade no vale do monte Ida. Esse culto é de uma "religião ateísta", pois pelo menos os membros mais refinados do grupo reconhecem que Cibele existe, na verdade, para "aquilo que faz parte de nós mesmos, mas que não ousamos reconhecer" (p.124). Uma sociedade completamente igualitária, na qual as mulheres escravas e serviçais são tratadas como filhas de sangue real; uma comunidade bem entrelaçada e baseada na divisão e doação, e na qual as atividades trazem à tona o ser humano por completo. Esse grupo restaura a crença de Cassandra na humanidade (que já se extinguia), "por ser diferente, por tirar de sua natureza qualidades que eu quase não ousara imaginar" (p.79). Formada principalmente por mulheres, essa sociedade não é excludente, pois possui o velho Anquises, um escultor de belos objetos em madeira, que ele dá de presente a outros. Possivelmente existe uma alusão a Ernest Bloch na figura de Anquises, pois ele "não se cansava de dizer que sempre seria possível" fazer aquilo que seu grupo fazia, isto é, "trazer um pequeno pedaço do futuro para o rígido presente...", e ele "ensinava os mais jovens a sonhar tendo os dois pés no chão" (p.134-5).

Então a comunidade de mulheres se torna um Vorschein blochiano: um vislumbre no presente do que poderia ser um futuro livre. Esse grupo sempre pensa no ser humano do futuro: "Acima de qualquer coisa, falamos sobre quem virá após nós. Como serão ... se irão preencher nossa omissão, consertar nossos erros" (p.132). Enquanto o grupo de Moskauer Novelle é afirmativo quanto ao futuro, o de Kassandra é interrogativo, pois Wolf não acreditou, por muito tempo, na inevitabilidade do mundo. O futuro permanece aberto nessa obra, a utopia se torna uma esperança.

Nas obras subseqüentes a Kassandra (Störfall, 1987; Sommerstück, 1989; Was Bleibt, 1990), o pessimismo de Wolf é aprofundado e a esperança parece diminuir perigosamente. O capitulo final de Christa Wolf's Utopian Vision, de Anna Kuhn, sobre Störfall, último dos livros de Wolf a surgir antes de ser publicado, levanta a questão da base da visão de Wolf não haver desmoronado com a pressão das últimas invenções. O subtítulo do capítulo de Kuhn aparece na interrogativa: "A destruição da utopia?". Se olharmos para os três últimos livros publicados até hoje, parece claro que, ao invés de uma tendência naquela direção, a questão deve ser mesmo respondida na negativa. 
Como bem aponta Kuhn, "a tensão entre a esperança e a descrença, tão característica da obra de Wolf desde No Place on Earth, é o princípio estrutural de Störfall" (1988, p.221). Diante do evento que gera esse texto, a explosão do reator nuclear em Chernobyl, o lado da descrença pesa mais na balança sem, contudo, esmagar por completo a esperança. Wolf agora vê o mundo moderno (que se coloca à margem da destruição, com Chernobyl) como um sistema no qual "tudo se encaixa...: o desejo da maioria das pessoas de ter uma vida confortável, a tendência a acreditar naqueles que discursam sobre palanques e nos homens de casaco branco ... parecem corresponder à arrogância, sede de poder, busca do lucro, curiosidade inescrupulosa e narcisismo de outros" (Wolf, 1989, p.17). O sistema é visto como bastante monstruoso, e a humanidade é vista como se houvesse se transformado em um monstro em relação à ordem natural. Os golfinhos, com "sua vida brincalhona e comportamento amigável", são comparados favoravelmente aos humanos; Wolfsente que, por mais que tentemos, "não podemos ser amigáveis", pois "aceitamos presentes de falsos deuses..." (p.98).

Mas ainda assim a ciência, a tecnologia e o "progresso" material e quantitativo que se tornaram deuses modernos não são rejeitados por si mesmos: o que se rejeita é o fato de eles terem sido elevados à condição de deuses, ou seja, de valores supremos que estão acima de todos os outros. Wolf reconhece o potencial do bem na ciência ao contrastar Chernobyl e a bem-sucedida operação de um tumor no cérebro à qual seu irmão foi submetido. E ainda, a narradora de Störfall projeta outros valores como uma alternativa forçosa para o ethos do mundo moderno: em particular, a própria "amizade", na qual ela passa a não acreditar, quando busca mentalmente seu irmão na mesa de operações, comunica-se com ele e o ajuda de forma intuitiva e não científica. O texto termina com uma nota sombria, com um sonho no qual uma voz grita: "Um monstro perfeito", e no qual uma "lua putrescente" desaparece de vista (p.109). Mas o tempo condicional da última frase - "Como seria difícil, meu irmão, partir dessa terra" - ainda deixa aberta a porta da esperança.

Embora a próxima obra publicada, Sommerstück, também não feche essa porta, a ênfase é dada ao erro e à resignação. Sommerstück retoma a tentativa de alguns amigos, artistas, intelectuais e outros que se sentem à margem de sua sociedade de conseguir uma comunidade satisfatória adquirindo, reformando e vivendo (parcialmente) em várias casas de camponeses em um vilarejo rural. Essa obra pode nos ajudar a entender por que a parte de Kassandra em Voraussetzungen não inclui nenhum encrave utópico, do tipo que é imaginariamente projetado no romance pelos adoradores de Cibele. Sommerstück se refere a uma experiência que ocorreu na vida de Wolf antes da composição de Kassandra, visto que suas primeiras versões foram escritas em fins da década de 1970 e início dos anos 80 (revista em 1987, a obra só foi publicada em 1989). Por Sommerstück ser a narrativa de uma utopia abortada, podemos deduzir porque Voraussetzungen de 1982-1983 não tinha esse assunto como tema. Em Kassandra como um todo, Wolf ainda queria levar adiante o princípio da esperança. 
A primeira página de Sommerstück diz ao leitor que a experiência está acabada, que o "destino" não quis que fosse bem-sucedida. E, perto do fim, Ellen, a personagem que mais se assemelha a Wolf, pensa sobre a idéia basicamente insatisfatória de um retiro para uma ilha de satisfação rural das pessoas que querem, na verdade, a transformação da sociedade como um todo. Todavia, o conteúdo do texto evoca muitos momentos de "mágica" e simpatia nas relações entre amigos, e de satisfação com a beleza de seu meio. Ao mesmo tempo, marca tensões e conflitos, e mostra como, mesmo nesse vilarejo, o meio natural e humano sofre as incursões da modernidade (também inclui a visão de um desastre ecológico iminente). O esforço para criar condições de vida inspiradas pelo passado é ameaçado todo o tempo e é, por fim, destruído. Significativamente, perto do fim, quando o grupo tem a idéia de escrever um livro em conjunto, como as oficinas de arte dos mestres do passado, alguém comenta que o presente não é o passado e que não possuem mais essa liberdade.

O último livro publicado, Was Bleibt, também a revisão de um texto escrito há muito tempo (primeira versão: 1979; revisão: nov. 1989; publicação: 1990), é uma narrativa das atividades e reflexões de um dia na vida da narradora. Um de seus enfoques principais é a possibilidade de um futuro diferente do presente. A situação é desanimadora, as expectativas vagas e, em uma passagem, a narradora percebe que a própria linguagem que usa para formular seu desejo mostra que já começou a pensar como os que governam o presente:

Se ao menos houvesse uma máquina que pudesse reunir toda a esperança que ainda existe no mundo e lançá-la como um raio laser nesse horizonte de pedra, derretendo-o e fazendo-o se abrir... Você já pensa como eles - máquinas, radiação, violência. Você está, agora, estendendo para o futuro o pouco do atual poder que detêm. E é dessa forma que colocariam você exatamente onde querem. (Wolf, 1993, p.270)

Entretanto, o condicional da última frase reafirma que nem tudo está perdido, e a conclusão total de sua obra restabelece com firmeza a perspectiva blochiana da esperança.

Em uma palestra dada pela narradora, no espaço reservado para perguntas, uma jovem perguntou sobre "como poderia nascer um futuro no qual nós e nossos filhos pudéssemos viver, partindo da situação atual?". A pergunta gera uma discussão acalorada sobre a idéia do futuro e, durante a discussão, alguém pronuncia delicadamente a utópica palavra "irmandade" e a atmosfera se torna leve, "como na véspera de uma celebração" (p.286-8). Os termos que Wolf utiliza para descrever esta cena não deixam dúvidas de que esta tornou-se um Vorschein de um futuro livre. No final dessa palestra, é revelado o significado do título - O que restou -: o futuro é o que restou, mostrando claramente que a utopia, para Christa Wolf, não foi totalmente destruída.

Was Bleibt também enfoca a perseguição da narradora pela Stasi, e é este aspecto da obra que a colocou em violenta controvérsia política logo após sua publicação. Por ter esperado para publicá-lo após a queda do Muro e do regime alemão-oriental, 
Wolf foi acusada de haver-se comprometido com o regime (foi chamada por alguns de Staatsdichterin). Mais lenha foi colocada na fogueira quando, em janeiro de 1993, Wolf revelou que ela mesma havia sido uma "colaboradora informal" da Stasi entre 1959 e 1962. Embora um estudo completo dessa questão esteja fora do intuito deste trabalho sobre a visão romântica/feminista de Wolf, apresentaremos, por fim, algumas considerações sobre essa controvérsia, principalmente até o ponto em que ela apresenta relação com nossa concepção sobre sua obra.

Sobre a real colaboração de Wolf com a Stasi, devemos enfatizar muitas coisas. Primeiro, esse "pacto com o demônio" aconteceu por um curto período, no início da carreira de Wolf, que corresponde à produção de Moskauer Novelle. Nesse período, Wolf era ainda bastante ingênua politicamente e possuía um forte "complexo de inferioridade" para com a aura antifascista dos líderes do governo. Era também uma colaboração limitada, cheia de receios e aparentemente pouco proveitosa para a Stasi (Gitlin, 1993). Mas o mais importante é que esse período terminou logo, o que não aconteceu com muitos outros artistas da Alemanha Oriental. ${ }^{18} \mathrm{~A}$ atitude de Wolf tornou-se cada vez mais crítica, e teve início em 1968 com sua recusa (apenas dela e de Anna Seghers) em assinar o termo de apoio da União dos Escritores à repressão Soviética na Tchecoslováquia; ela tornou-se suspeita e foi assediada pela Stasi por um tempo muito mais longo (mais de 20 anos) do que o curto período em que colaborou com esse órgão.

Quanto às dúvidas lançadas sobre a posição de Wolf no período posterior, sugerindo que ela fosse culpada de hipocrisia, parecem ser injustas. Como notou um de seus defensores entre os intelectuais de renome, Günter Grass, até o fim ela nunca abandonou a esperança da possibilidade de uma mudança na sociedade do Leste alemão. ${ }^{19} \mathrm{Na}$ verdade, para a sensibilidade utópico-romântica de Wolf, o Ocidente capitalista, a própria raiz da modernidade, nunca foi uma alternativa atraente. E as chamadas nações "socialistas", embora tenham disfarçado o fato, haviam sido fundadas sobre um projeto emancipador. Assim, Christa Wolf escolheu o caminho contraditório de testemunhar a esperança utópica de verdadeira realização humana individual dentro do confinamento do "socialismo real". Devemos admitir, assim como ela mesma o faz, que sua crítica política do regime alemão-oriental foi insuficiente; entretanto, suas realizações como escritora de longe superam essa fraqueza. Como notou David Bathrich, embora nunca tenha questionado as estruturas políticas fundamentais da RDA (o sistema unipartidário, a falta de democracia), ela é "alguém que, no momento do perigo, disse o que não se podia dizer", denunciando aspectos da sociedade alemã-oriental que se assemelhavam ao Ocidente, criando também uma "verdadeira alternativa cultural" (Bathrick, s.d., p.10-1), que, acrescentaríamos, é indissoluvelmente feminista e romântica.

\footnotetext{
18 Ver "Sleeping with the enemy: Stasi and the literati". Newsweek, 8 fev. 1993; e "Intellectuels est-allemands sur la sellette", Le Monde Diplomatique, p.11, abr. 1993.

19 Le Monde Diplomatique, p.11, abr. 1993.
} 
SAYRE, R. LÖWY, M. Romanticism as a feminist vision: the quest of Christa Wolf. Trans/Form/Ação (São Paulo), v.19, p.9-33, 1996.

- ABSTRACT: Few modem authors have given such powerful expression to the "elective affinity" between romanticism and feminism as Christa Wolf. When we refer to her as a romantic writer, we not only take into account her explicitinterest in romantic women authors from the early 19th century, such as Caroline von Günderrode and Bettina von Arnim, but also, and above all, her own romantic worldview, and its relationship to marxism and feminism.

- KEYWORDS: Romanticism; feminism; marxism; German Democratic Republic; industrial civilization.

\section{Referências bibliográficas}

BATHRICH, D. Intelectuals after Stalin. S.l.: s.n., s.d. p.10-11.

EZERGAILIS, I. Woman Writers - The Divided Self. Bonn: Bouvier Verlag, 1982.

FEHERVARY, H., LENNOX, S. Introduction. In: WOLF, C. Self-Experiment: Appendix to a

Report. New German Critique, v.3, p.111-2, 1978.

GITLIN, T. I did Not Imagine that I Lived in Truth. New York Times Book Review, 4 abr. 1993. HERZIGER, R., PREUSSER, H.-P.Text und Kritik. Sonderband. München: H. L. Arnold, 1991. HUYSSEN, A. Christa Wolf Materialienbuck. Darmstadt: Luchterland, 1979.

INTELLECTUELS est-allemands sur la sellette. Le Monde Diplomatique, p.11, abr. 1993.

KUHN, A. K. Christa Wolf's Utopian Vision: from Marxism to Feminism. New York: Cambridge University, 1988.

LOVE, M. Christa Wolf and Feminism: Breaking the Patriarchal Connection. New German Critique, v.16, 1979.

LÖWY, M. Redemption and Utopia. Libertarian Judaism in Central Europe. A Study of Elective Affinity. Stanford: Stanford University, 1992.

ROSSO, G. A., WATKINS, D. P. Spirits of Fire: English Romantic Writers and Contemporary Historical Methods. London: Associated University, 1990.

SAYRE, R., LÖWY, M. Figures of Romantic Anti-Capitalism. New German Critique, v.32, 1984. Révolte et mélancolie: le romantisme à contre-courant de la modernité. Paris:

Payot, 1992.

SLEEPING with the Enemy: Stasi and the Literati. Newsweek, 8 fev. 1993.

TROTTEN, N. Zur Aktualität der Romantik in der DDR: Christa Wolf und ihre Vorläufer.

Zeitschrift für deutsche Philologie, v.101, n.1, 1982.

WOLF, C. Moskauer Novelle. Halle: Mitteldeutscher Verlag, 1961.

Lesen und Schreiben. Darmstadt: Luchterhand, 1972.

Divided Heaven. New York: Adler's Foreign Books, 1976.

Self-Experiment: Appendix to a Report. New German Critique, v.13, 1978.

Lesen und Schreiben. Neue Sammlung. Neuwied: Luchterhand, 1980.

Kein Ort. Nirgends. Neuwied: Luchterhand, 1981a.

Neue Lebensansichten eines Katers. In:

Gesammelte Erzählungen.

Frankfurt: Luchterhand, 1981b. 
WOLF, C. Der Schatten eines Traumes. In: (Org.) Karoline von Günderrode, der

Schatten eines Traumes. Gedichte, Prosa, Briefe, Zeugnisse. Darmstad und Nerwied:

Luchterhand, 1981c, p.7-10.

Kassandra: A Novel and Four Essays. New York: Farrar, Straus, Giroux, 1984.

Ansprachen. Darmstadt: Luchterhand, 1988a.

. The Fourth Dimension: Interviews with Christa Wolf. London: Verso, 1988b.

The Quest for Christa T. London: Virago, 1988c.

Accident. London: Virago 1989.

What Remains and other Stories. London: Virago, 1993.

ZIPES, J. Introduction. In: WOLF, C. Divided Heaven. New York: Adler's Foreign Books, 1976. 